\title{
Estéticas vivas sobre la muerte joven. La protesta social en torno a la violencia letal en la ciudad de Rosario
}

\author{
Living Aesthetics About Young Death. Social Protest Around Lethal Violence in \\ the City of Rosario
}

\author{
Estéticas vivas sobre a morte jovem. Os protestos sociais em torno da violência \\ letal na cidade de Rosario
}

Marilé Di Filippo

mariledifilippo@gmail.com

Universidad Nacional de Rosario, Argentina

Universidad de Buenos Aires, Argentina

Recepción: 05 Mayo 2021

Aprobación: 21 Junio 2021

Publicación: 01 Diciembre 2021

Cita sugerida: Di Filippo, M. (2021). Estéticas vivas sobre la muerte joven. La protesta social en torno a la violencia letal en la ciudad de Rosario. Aletheia, 12(23), e106. https://doi.org/10.24215/18533701e106
Resumen: En este artículo abordamos las modulaciones estéticas de la protesta social contra la violencia letal en la ciudad de Rosario (Argentina), tomando como casos el repertorio en torno al Triple Crimen de Villa Moreno encabezado por el Movimiento 26 de Junio entre los años 2012-2014 y los repertorios contra la violencia institucional impulsados por la Multisectorial Contra la Violencia Institucional durante el año 2020. En primer término, indagamos en la dimensión estética de la protesta social de ambos repertorios (espacialidad, temporalidad, morfología y semiología) y, en segundo lugar, sobre sus recursos expresivos artísticos. Nos proponemos analizar las principales coordenadas del escenario manifestante emergido en el año 2012 que permitió, a través de singulares estrategias estéticas de politización de la violencia, enunciar las modalidades de la violencia letal sobre jóvenes de sectores populares así como promover su asunción como una problemática que atañe al conjunto del cuerpo social. Asimismo, nos preguntamos por las continuidades y discontinuidades experimentadas en dichos repertorios contra la violencia letal desde la emergencia sanitaria originada con motivo de la propagación del Covid-19. Por último, en las reflexiones finales, sintetizamos los principales hallazgos de investigación y deslizamos nuevos interrogantes sobre el tiempo presente de la protesta.

Palabras clave: Estética, Política, Violencia letal, Repertorios de protesta, Rosario.

Abstract: This article will study the aesthetic modulations of social protest against lethal violence in the city of Rosario (Argentina), taking as cases the repertoire around the Triple Crime of Villa Moreno led by the social organization Movimiento 26 de Junio between the years 2012-2014 and the repertoires against institutional violence promoted by the Multisectorial Contra la Violencia Institucional (Multi-sector Organization Against Institutional Violence) during 2020. First of all, the aesthetic dimension of social protest in both repertoires (spatiality, temporality, morphology, and semiology) is investigated. Secondly, the artistic expressive resources are studied. The purpose is to analyze the main coordinates of the 
demonstrating scene that emerged in 2012. Through unique aesthetic strategies of politicization of violence, it allowed to enunciate the modalities of lethal violence against young people from popular sectors as well as to promote its recognition as a problem that concerns the entire social body. Likewise, the continuities and discontinuities experienced in such repertoires against lethal violence since the health emergency caused by the spread of COVID-19 are pondered. The final reflections synthesize the main research findings and posit new questions about the present time of the protest.

Keywords: Aesthetics, Politics, Lethal violence, Repertoires of protest, Rosario.

Resumo: Nesse artigo abordamos as modulações estéticas dos protestos sociais contra a violência letal na cidade de Rosario (Argentina), tomando como casos o repertório ao redor do Tríplice Crime de Villa Moreno comandado pelo Movimento 26 de junho entre os anos 2012-2014 e os repertórios contra a violência institucional movidos pela Multisectorial contra la Violencia Institucional durante o ano de 2020. Em primeiro lugar, indagamos a dimensão estética do protesto social de ambos os repertórios (espacialidade, temporalidade, morfologia e semiologia) e, em segundo lugar, sobre seus recursos expressivos artísticos. Propomo-nos analisar as principais coordenadas do cenário manifestante surgido no ano de 2012 que permitiu, por meio de singulares estratégias estéticas de politização da violência, enunciar as modalidades da violência letal sobre os jovens de setores populares assim como também promover a sua tomada como uma problemática no que se refere ao conjunto do corpo social. Do mesmo modo, nos perguntamos pelas continuidades e descontinuidades experimentadas naqueles repertórios contra a violência letal vista a partir da emergência sanitária originada pela propagação da Covid-19. Por último, nas reflexões finais, resumimos as principais descobertas de investigação e sugerimos novos questionamentos a respeito do tempo presente dos protestos.

Palavras-chave: Estética, Política, Violência letal, Repertórios de protesta, Rosário.

\section{INTRODUCCIÓN}

Capitalismo artístico, creativo o transestético (Lipovetsky y Serroy, 2015), semio-capitalismo (Berardi, 2014), capitalismo de ficción o teatral (Verdú, 2003), modo artístico de producción (Rosler, 2017), era de la producción artística masiva (Groys, 2014) son modos de nombrar el protagonismo que la dimensión estética adquiere en el actual modo de acumulación. Señalan transformaciones que fueron tempranamente advertidas por Guy Debord o Jean Baudrillard, entre otros, en sus teorizaciones sobre la sociedad del espectáculo o la noción, a secas, de transestética.

Siguiendo a Ileana Diéguez (2013), y los aportes de Elsa Blair (2005), advertimos que el espesor que la estética adopta en la configuración social debe ser puesto en correlación con los escenarios de la violencia inherentes también al modo de producción. Diéguez, retomando la idea de capitalismo teatral, propone citando a Calabrese, la noción de época neo-barroca, aludiendo a que esta fase histórica supone una sensorialidad y una visualidad desbordadas en el espacio cotidiano. "Lo demasiado" se instaura como 
normalidad, implicando también una construcción de lo visual que toma al cuerpo como plataforma o materia de sus extremas representaciones.

Retomando la noción de necropolítica de Mbembe plantea el concepto de necroteatro para referir a las teatralidades distópicas que son fundacionales del poder. Escenificaciones que exponen las muertes violentas como acontecimientos de representación y producción de un necropoder y que producen dramaturgias del miedo, en las que, además de la muerte, se decide sobre los modos de sufrir y aniquilar la condición humana de aquellos cuerpos que se toma como propios. De este modo, la violencia tiene un fuerte componente estético.

La estética es, al mismo tiempo, un territorio de fabulación de resistencias, de formas creativas y de relacionalidad que pueden visibilizar y denunciar la violencia extrema, politizar el dolor y generar modos de responder colectivamente a situaciones de desgarramiento vital. Estas dos zonas del par estética/violencia (la estética de la violencia y las estéticas sobre/contra la violencia) reponen un doble registro del cuerpo: en el primer sentido como geografía sobre la que se instalan relatos de poder, en el segundo, del que nos ocuparemos fundamentalmente aquí, como objeto-sujeto de representación artística (Diéguez, 2013).

La ciudad de Rosario (Argentina) en la última década ha sido sede una serie de imaginaciones estéticopolíticas que configuraron repertorios de protesta (Auyero, 2002) ante casos de jóvenes asesinados por fuerzas policiales, en episodios de linchamiento o por organizaciones vinculadas al mercado de drogas ilegales.

Estas acciones que inauguraron un nuevo ciclo de protesta social local se inscriben en una densa genealogía estético-política. Rosario, con similitudes y diferencias con otras ciudades del país, tuvo desde mediado/ fines de la década del 90' dos ciclos de protesta más, que hemos reconstruido y sistematizado en otras investigaciones. El primero desarrollado entre los años 1995/7-2005, tuvo como epicentro la crisis social, económica y política de finales de los años noventa y la insurrección popular del 19 y 20 de diciembre de 2001. En ese momento emerge un nuevo protagonismo social que abarca desde los llamados nuevos movimientos sociales, pasando por subjetivaciones políticas más esporádicas, hasta ingeniosos colectivos de activismo artístico (Longoni, 2009; Expósito, Vidal y Vindel, 2012) que tienen allí su tiempo de esplendor. Hacia mediados de la década del 2000 paralelo a la recomposición socio-económica y a la estabilización macropolítica e institucional, toma forma otro ciclo con notables diferencias que se extiende, para el caso rosarino, durante el período 2005-2012.

Los activismos contra la violencia letal componen, como decíamos, un tercer tiempo activista del que formaron parte también protestas ocasionadas en respuesta a las políticas económicas, sociales, científicas y de Derechos Humamos del gobierno de la alianza Cambiemos (2015-2019), el activismo producido por el movimiento de mujeres, feminista y de la diversidad sexual así como manifestaciones de actores colectivos con distintos grados de organización que podríamos denominar como punitivos y/o neo-conservadores.

Centrándonos en el activismo contra la violencia letal, en esta ocasión posamos la mirada sobre dos casos de análisis. Por una parte, abordamos el repertorio de protesta desarrollado con motivo del Triple Crimen de Villa Moreno (TCVM) entre los años 2012 y $2014^{1}$ impulsado por el Movimiento 26 de Junio (M26) ${ }^{2}$ y, por otra, acciones contra la violencia institucional llevadas a cabo durante el año 2020 por la Multisectorial Contra la Violencia Institucional (MCVI) ${ }^{3}$. Pretendemos analizar las prácticas artísticas de protesta, así como las formas de composición, montaje y aparición no necesariamente artísticas que toda praxis política supone y que configuran lo que, retomando el gesto epistemológico de Jacques Rancière (2005, 2007 y 2009), denominamos como la dimensión estética de la protesta social.

Como hipótesis sostenemos que a comienzos de la segunda década del milenio se visibiliza en Rosario una nueva conflictividad social que moviliza la emergencia de un nuevo ciclo de protesta que, a través de la dimensión estética de la protesta y de las prácticas artísticas de los repertorios, genera la posibilidad de enunciar y denunciar las modalidades de la violencia letal sobre jóvenes de sectores populares y promueve la asunción y elaboración de dicha violencia como una problemática que atañe al conjunto del cuerpo social. A partir de la emergencia sanitaria originada con motivo de la propagación del Covid-19 tales repertorios 
contra la violencia letal experimentan transformaciones pero también registran persistencias que colocan la pregunta en torno a la continuidad o la configuración de un nuevo escenario activista.

\section{LA DIMENSIÓN ESTÉTICA DE LA PROTESTA SOCIAL CONTRA LA VIOLENCIA LETAL}

En las primeras horas del 1 de enero de 2012 en la zona sur de la ciudad de Rosario, tres jóvenes militantes del M26 -Jeremías Trasante, Claudio “Mono" Suárez y Adrián "Patom” Rodríguez- se encontraron en la cancha de fútbol del barrio para recibir el año nuevo. Minutos después, alumbrados por linternas, ingresaron al descampado que circunda las instalaciones del Club Agrupación Infantil Oroño integrantes de una organización criminal vinculada al mercado de drogas ilegales. Una vez ahí, sin casi mediar interlocución, abrieron fuego indiscriminadamente sobre los jóvenes. Luego, dispararon en abanico con un saldo de otras tres personas heridas. Según consta en las investigaciones judiciales y extra-judiciales los tres jóvenes fueron confundidos con miembros de otro grupo rival dedicado también a la venta de drogas ilegales. Este hecho fue nombrado como el Triple Crimen de Villa Moreno.

Dos años después, en octubre de 2014, un joven oriundo de la localidad bonaerense de Florencio Varela desaparece en la ciudad de Rosario. Casi un mes después de que sus familiares iniciaran la búsqueda, mientras se desconcentraba una movilización en la que se exigía su aparición con vida frente a la comisaría donde había sido visto por última vez, su cuerpo apareció flotando en las aguas del Río Paraná. El caso de Franco Casco, junto a los de Jonatan Herrera ${ }^{4}$, Gerardo “Pichón” Escobar ${ }^{5}$, Maximiliano Zamudio ${ }^{6}$, David Campos y Emanuel Medina ${ }^{7}$, entre otros, dio inicio a un renovado activismo contra la violencia institucional que se inscribió en la línea trazada por el repertorio en torno al TCVM. Los familiares de estos jóvenes, junto a otros familiares de víctimas y militantes de distintas organizaciones sociales compusieron la Multisectorial Contra la Violencia Institucional. Un nuevo organismo de derechos humanos que sostiene su protagonismo en la escena local, colocando con sus repertorios actuales la pregunta por las continuidades y rupturas que instaura el tiempo pandémico.

Fellieule entiende a la manifestación callejera como la ocupación momentánea, por varias personas, de un lugar abierto (público o privado) y que directa o indirectamente conlleva la expresión de opiniones políticas (Fellieule y Tartakowsky, 2015). Este recurso constituyó la matriz del repertorio de acción colectiva por el TCVM, adoptando modalidades clásicas tales como marchas, concentraciones, vigilias y acampes y otras más novedosas como caravanas de autos.

Las marchas fueron dentro de las manifestaciones callejeras la acción más repetida. Se realizaron treinta y cuatro en los casi tres años que duró el repertorio. Se repitieron mes a mes desde el asesinato hasta el juicio consumado en noviembre de 2014. La centralidad de este recurso responde a una tradición de la protesta social argentina, que fue de la mano, desde mediados de la década del 2000, de un progresivo proceso de abandono de otras dinámicas de acción directa (como los piquetes, bloqueos y tomas) que caracterizaron las acciones de los movimientos sociales argentinos de fines de la década del 90 y los primeros 2000. A partir del 2020, como veremos, esta constante experimentó algunas transformaciones.

Tal como aseveran Fellieule y Tartakowsky (2015) la manifestación callejera introduce una relación distanciada en el tiempo de la política, supone una serie de mediaciones que procesan y evitan la confrontación directa, a diferencia de las medidas más inmediatistas como las insurrecciones, concentraciones o levantamientos espontáneos.

Analizando la escenificación de las manifestaciones los autores distinguen tres aspectos: a) el espacio, b) la temporalidad y c) la morfología; a lo que adhieren, posteriormente, d) la semiología manifestante. Por nuestra parte, ubicamos estos componentes como parte de la dimensión estética de la protesta social. Y sumamos e) los recursos expresivos artísticos que los manifestantes utilizan, situándonos en una interfaz entre los trabajos provenientes del campo de estudios sobre la acción colectiva y del activismo artístico (Vich, 2004 y 2015; 
Holmes, 2012; Expósito, 2012 y 2014; Scribano y Cabral, 2009; Chávez Mac Gregor, 2009 y 2015; Diéguez, 2007; Longoni, 2007 y 2009, Pérez Balbi, 2020; Gutiérrez y Cuello, 2016, etc.).

\section{Geografías de la protesta}

La espacialización del repertorio por el TCVM obedeció a los patrones convencionales de la protesta, desarrollándose en (o entre) los lugares neurálgicos donde se territorializa el poder político o judicial (Tribunales, Sede de Gobierno, etc.). En otros casos, conectando estos espacios con sitios de pertenencia de los militantes asesinados (por ejemplo, las marchas que partieron del barrio donde vivían y militaban los jóvenes o desde el lugar donde fueron asesinados). De este modo, mientras que las marchas supusieron desplazamientos, trazar recorridos entre lugares (desde un centro de poder a otro o desde los lugares propios a los centros de poder), las concentraciones, actos, acampes y vigilias tuvieron un carácter estático e invasivo, imprimiendo las exigencias en esos sitios emblemáticos.

Si bien, tal como han señalado diversos autores, las espacialidades pandémicas se han visto reducidas a los balcones, esquinas, veredas y, fundamentalmente, a las pantallas (Proaño Gómez y Verzero, 2020), en las acciones contra la violencia institucional realizadas por la MCVI durante el año 2020 apreciamos diferentes intervenciones que, conjugando dinámicas virtuales y de presencialidad acotada, sostuvieron cierta continuidad con la espacialidad pre-pandemia, a pesar de la imposibilidad de habitar el espacio público.

Tal es el caso de la marcha de pasacalles, una de las acciones organizadas en el marco de la sexta Marcha Nacional contra el Gatillo Fácil -que constituyó la cuarta edición local-. La acción concretada el 27 de agosto consistió en instalar pasacalles con las consignas acordadas por las organizaciones convocantes y otras alusivas a la lucha contra la violencia institucional a lo largo del recorrido que realiza todos los años el colectivo manifestante: desde Tribunales Provinciales hasta la Sede de Gobernación. Asimismo, el Centro de Justicia Penal fue el lugar escogido para realizar otras instalaciones gráfico-performáticas, que analizaremos en apartados venideros. Otro tipo de intervenciones consistió en la realización de ollas populares en los barrios donde vivían los jóvenes o donde viven ahora sus familias en ocasión de cumpleaños de las víctimas o al conmemorarse un nuevo aniversario de su asesinato. Tal es el caso de la olla popular por Franco Casco, por Jonatan Herrera o por Maximiliano Zamudio, las cuales continuaron con diversa periodicidad en los meses siguientes.

De este modo, si bien estos espacios pudieron ser ocupados acotadamente por la corporalidad colectiva, se sostuvieron los sitios emblemáticos de la espacialidad manifestante, tales como los centros neurálgicos del poder judicial y político, viéndose fortalecida en pandemia la espacialidad vinculada a los territorios propios, privados o íntimos de las víctimas en los que se desarrollaron las ollas populares. Actividades que, por lo demás, recuperaron una tradición de organización colectiva de la comida emblemática del primer ciclo que protesta que distinguimos a partir de los años 90 y los primeros 2000.

Resta subrayar, a pesar de estas permanencias, el nuevo impulso que como veremos en lo que sigue tomó la virtualización de la protesta, que subrayó esa zona del espacio público como territorio destacado de la manifestación social dando a las tecnopoéticas (Kozak, 2015) o a los activismos tecnopolíticos (Fuentes, 2020) un nuevo impulso que robustece la soberanía digital.

\section{Entre tiempos}

En cuanto a la temporalidad manifestante podemos distinguir para el caso del repertorio por el TCVM tres dinámicas específicas. En primer lugar, una dinámica conmemorativa, pero de duración reducida. Es decir, una temporalidad insistente, cíclica, repetitiva, que contribuyó a la ritualización del proceso de lucha. Tal es 
el caso de las manifestaciones que se realizaron los primeros días de cada mes conmemorando el 1 de enero, día en que sucedió la masacre.

En segundo lugar, una dinámica de presión directa con duración dilatada en la cual el momento de realización y la extensión del horizonte temporal de la medida correspondió con instancias decisivas o situaciones urgentes, mientras que la temporalidad cíclica, repetitiva desempeñó, más bien, una función de memoria. Aludimos a acciones que ocurrieron en fechas claves para el proceso judicial. Por ejemplo, en noviembre de 2014 cuando comenzó el juicio oral se montó un acampe frente a los tribunales, precedido por una vigilia, que permaneció hasta su finalización en el mes de diciembre. Asimismo, esta temporalidad fue escogida para visibilizar demandas específicas de resolución urgente. Por ejemplo, en agosto de 2012 se montó un acampe que tenía como fin lograr una audiencia con el Gobernador de la Provincia de Santa Fe para exigir protección a los familiares de las víctimas amenazados por las organizaciones criminales.

En tercer lugar, el repertorio se compuso de una temporalidad inesperada, de carácter sorpresivo y de desarrollo intenso y elíptico, tales como las interpelaciones públicas que consistieron en apariciones inesperadas en actos o acontecimientos de los que participaban funcionarios políticos para plantearles determinadas demandas. Por ejemplo, en agosto de 2012 los manifestantes interrumpieron un acto del que participaba el Gobernador de la Provincia de Santa Fe. Con banderas, pancartas y cánticos persiguieron a las autoridades, en pleno desarrollo de la actividad oficial, donde interpelaron públicamente al mandatario.

Dicha acción encuentra cierta vinculación con los escraches a genocidas llevados adelante fundamentalmente por el movimiento de derechos humanos durante los dos ciclos de protesta anteriores, así como por otras organizaciones sociales a funcionarios políticos. Sin embargo, a diferencia de tales medidas, se apeló en el caso del TCVM a la figura de la interpelación, esperando una respuesta de las autoridades en cuestión y la temporalidad no era definida por las organizaciones, sino que se supeditaban a la agenda de las autoridades a las que se pretendía incomodar, usurpando la temporalidad ajena como condición de construcción del propio tiempo.

En las acciones consumadas por la MCVI durante el año 2020 identificamos la presencia de las dos primeras temporalidades señaladas. Por una parte, una dinámica conmemorativa pero reducida en el tiempo que se desarrolló en actividades que conforman la agenda anual de las organizaciones contra la violencia institucional. Por ejemplo, las desarrolladas en el marco de la Marcha Nacional Contra el Gatillo Fácil u otras correspondientes al calendario de las organizaciones de derechos humanos argentinas (como el 24 de marzo Día de la Memoria, la Verdad y la Justicia, el 8 de mayo Día Nacional de Lucha Contra la Violencia Institucional, el 10 de diciembre Día Internacional de los Derechos Humanos, entre otros). También en esta línea se ubican las sucedidas en fechas de cumpleaños o de aniversarios de desapariciones o asesinatos de los jóvenes cuyas causas nuclea la organización u otros emblemáticos del movimiento de derechos humanos a nivel nacional (como el 1 de agosto por la desaparición seguida de muerte de Santiago Maldonado o el 18 de septiembre por la segunda desaparición de Jorge Julio López).

Por otra parte, advertimos una temporalidad de presión directa con duración dilatada en jornadas como las que tuvieron lugar durante procesos judiciales que se celebraron en el año 2020. Tal el caso de las actividades llevadas a cabo en el marco de los juicios orales y públicos por el asesinato de Maximiliano Zamudio y por los fusilamientos de David Campos y Emanuel Medina. Consistieron en concentraciones diarias de familiares, amigos y militantes en los alrededores del Centro de Justicia Penal, aunque bajo una dinámica de distanciamiento y de rotación de cuerpos que difiere de los acampes o concentraciones realizadas años anteriores en los que la presencia masiva de los cuerpos juntos se constituía en el principal recurso para presionar al Poder Judicial y evidenciar la fortaleza del colectivo manifestante.

Ahora bien, en el 2020 todas las intervenciones con presencia offline tuvieron réplica o continuidad online. Otras fueron enteramente virtuales como la campaña \#AgitemosLasRedes, en el marco de la semana de la Marcha Nacional contra el Gatillo Fácil y el inicio del juicio por el asesinato de Maximiliano Zamudio. Se trató de una convocatoria dirigida a artistas, fotógrafos y a toda persona interesada, para subir a sus redes 
sociales fotos y/o dibujos alusivos a la lucha contra la violencia institucional o de los rostros de los jóvenes asesinados por la policía de Santa Fe. También se podía participar a través de poesías o textos. Los materiales debían ser compartidos con hashtag alusivos en las redes personales y luego en las redes de la MCVI.

Proaño Gómez ha señalado que la poética pandémica se caracteriza por una temporalidad y una espacialidad recortada en medio de una situación vital signada por la paralización del tiempo y la inmovilidad social. Afirma que asistimos al despliegue de una dramaturgia del encierro tanto en la teatralidad real como en la teatralidad de la escena. A su entender: "la estructura de esta obligada dramaturgia se conforma con ciertas características: la distancia, el aislamiento y la limitación del espacio (...)” (Proaño Gómez y Verzero, 2020, p. 30). Advierte la configuración de un presente intenso que supone, a su vez, una temporalidad alargada y vacía y procesos de interiorización, de búsqueda e intromisión en nuestras propias historias y pasados íntimos que son compartidos virtualmente en la conformación de un presente que pivotea entre un ayer y un futuro incierto.

La campaña \#AgitemosLasRedes y su propuesta de rastrear imágenes de vivencias propias de protesta parece inscribirse en este proceso de interiorización transmitido por las redes. Despliegue que, a su vez, es concomitante a la virtualización de los espacios propios, a esa conversión del espacio privado y, en ocasiones, de la propia intimidad en territorio soporte de las espacialidades públicas.

En síntesis, en los repertorios pandémicos se reiteran dos de las temporalidades manifestantes prepandémicas pero pierde entidad la temporalidad inesperada, disruptiva, de carácter sorpresivo y de desarrollo intenso, acorde a lógicas acontecimentales garantizadas por la presencia física. Y, en cambio, toma cuerpo una temporalidad asociada al presente intenso hiper-virtualizado al interior del tiempo alargado y, en cierta medida suspendido, de la vida social.

\section{Las formas de los cuerpos (que) dicen}

En lo que respecta a la morfología, la disposición del colectivo manifestante del TCVM supuso la jerarquización entre cabecera y cuerpo que operó en función de una división entre familiares directos de las víctimas, activistas del M26 y el resto de las organizaciones que se plegaron al reclamo. De este modo, primó el funcionamiento compacto, cuan gigante vertebrado del cuerpo colectivo de la manifestación.

En cuanto a los modos en que se dispusieron los cuerpos individuales, reconstruimos dos características distintivas. Por una parte, la progresiva homogeneización visual. Y, por otra, la escenificación de un ánimo guerrero, a partir de la utilización de ciertos elementos como antorchas y cánticos.

A diferencia de repertorios de ciclos anteriores caracterizados por la adquisición de cierta diversidad que asociamos a un proceso de carnavalización de la protesta, en este repertorio apreciamos una recomposición de la cromaticidad en los colores rojo y negro, a partir de la indumentaria y en objetos como las pancartas y banderas, conformando columnas unificadas. Advertimos, así, una homogeneización de los manifestantes que mostró cierto poderío, una pretendida imagen de unidad y fortaleza política.

Para Holmes (2005) y Expósito (2005) la carnavalización de la protesta es una tendencia que aparece entre mediados y fines de los 90' de la mano de movimientos de resistencia en diferentes partes del mundo. Buena parte de las expresiones del ciclo de protesta iniciado en nuestro país promediando la década de los 90 podrían ubicarse en esta línea hermanadas, en el caso rosarino al menos, con la estética-en-la-calle festiva generada por el renacimiento del carnaval y el surgimiento de un nuevo movimiento murguero. En el ciclo de protesta siguiente (2005-2012) la condición festiva, o las disciplinas políticas felices al decir de Holmes, se convirtieron en una premisa obligada de las comparecencias (Didi-Huberman, 2014) de los movimientos sociales de nuevo cuño.

En los inicios del repertorio por el TCVM este elemento cede paso a la unificación del cuerpo manifestante, cuestión que por sí sola no detiene el proceso de carnavalización pero marca algunos matices. Esta dinámica 
también se vincula con el devenir electoral de estos movimientos sociales ${ }^{8}$ que, paralelamente al transcurso de este ciclo de protesta, conformaron frentes electorales, lo que produjo que la gramática y la estética partidaria transformara parte de la escenificación movimentista.

Lo dicho se enlaza con la expresividad de cierto ánimo guerrero, dramaturgia lograda a partir de la utilización de elementos con fuego, fundamentalmente antorchas y bengalas. Las marchas de antorchas por la noche fueron una de las medidas más reiteradas junto con las vigilias que si bien, por un lado, pueden asociarse a cierto estado doloso, su contracara parece ser insuflar ánimo guerrero ${ }^{9}$. Las marchas de antorchas se realizaron en diferentes fechas claves para el repertorio: en ocasión de conmemorar aniversarios del asesinato (por ejemplo, al cumplirse dos años, el 2 de enero del año 2014), así como el día anterior al comienzo del juicio, el 11 de noviembre del mismo año. Las antorchas se utilizaron también en festivales u otras manifestaciones y fueron habituales en los repertorios de protesta contra la violencia institucional, previos a la emergencia sanitaria.

El poder de los cuerpos juntos o de los cuerpos aliados (Butler, 2017) resulta una de las transformaciones más importantes de la escena pandémica. La marcha de pasacalles organizada por la MCVI resulta una experiencia significativa al respecto. Un recorrido sin cuerpos, una marcha de consignas inscriptas, materializadas en un dispositivo visual que cruza de modo transversal las calles que son generalmente transitadas en dirección recta por los manifestantes. La lona extendida señaliza la ausencia de los cuerpos a la vez que los coloca espectralmente en escena. Están y no están. No están físicamente, empero están en tanto las piezas gráficas convocan la memoria de su paso arraigada en el territorio. ¿Qué dicen esos cuerpos manifestantes (ahora ausentes) sobre los cuerpos arrasados por la violencia letal?, ¿qué enuncian los cuerpos ausentados por miedo a la muerte de los que están muertos?

Las consignas de los pasacalles incluían frases como "No más desaparecidos en democracia. Memoria, verdad y justicia”, "Ni un pibx menos, ni una bala más. El Estado es responsable”, "Cuando la justicia es ciega, organizarse es urgente" y otras con los nombres de los jóvenes asesinados seguidos por la palabra "Presentes". Cada uno recupera un eslabón de la semiología manifestante contra la violencia institucional y se construye sobre los sentidos abiertos por el movimiento de derechos humanos en Argentina.

Asimismo encuentran en el camino trazado por la semiología manifestante del TCVM la posibilidad de su enunciación situada. De hecho, los dos propósitos semiológicos del repertorio por el TCVM fueron: a) la des-criminalización de los jóvenes; y b) la transversalización a todo el cuerpo social de la preocupación por este caso considerado como una problemática de seguridad pública, tanto por su vinculación con el avance de la criminalidad de organizaciones vinculadas al mercado de drogas ilegales como a la connivencia policial.

La primera de las operaciones estuvo dirigida a contrariar la versión oficial brindada por la policía y por los medios de comunicación que, rápidamente, caratularon el hecho como un "ajuste de cuentas" entre organizaciones criminales, es decir como un acontecimiento dentro de esa economía delictual asociando la figura de los jóvenes a dichos grupos ${ }^{10}$. A lo que se sumó la falsa imputación de antecedentes penales.

"Ningún ajuste de cuentas, asesinaron a 3 pibes inocentes" ${ }^{11}$, fue el título del primer comunicado de desagravio del M26 tras la masacre. Allí desmienten que tuvieran antecedentes penales a la vez que destacan características de los jóvenes. Incluso, compilaron un libro cuyo título comienza con la afirmación "Soldaditos de nadie".

En este sentido, a la par que apreciamos la construcción de una imagen pública de los jóvenes que repone una serie de características a ellos asociadas (como la solidaridad, jovialidad, su condición de militantes y trabajadores), el repertorio se focaliza en la figura de la víctima, pero de una víctima que, a medida que avanza el proceso de protesta, puede ser universalizable al resto del cuerpo social, tal como veremos al analizar los recursos expresivos artísticos. Esta estrategia conlleva, no obstante, complejidades en las que no podemos adentrarnos aquí asociadas a la introducción de criterios moralizantes que contribuyen a la construcción de buenas y malas víctimas a las que se asocian juicios de merecimiento. 
En cuanto al segundo punto, si bien aparecen algunas consignas que retoman enunciados manifestantes de las gramáticas de la protesta argentina, tales como los clásicos pedidos de justicia ("Justicia por Jere, Mono y Patom"; "Sólo pedimos justicia”) o las que reivindican frases emblemáticas de repertorios anteriores (por ejemplo: "Mientras sigamos luchando, ellos seguirán presentes", "No están solos” y "Patóm, Jere y Mono, siempre presentes" "Ni un pibe menos") a las que se sumaron enunciados improvisados (como "Basta de narcotráfico", "Con los pibes no", "No queremos vivir con miedo" y "Un mes sin el Jere, el Mono y el Patóm. La bronca y la tristeza brotan desde las barriadas y golpean la puerta de los Tribunales"), a medida que avanzó el repertorio la consigna que lo distinguió y que se condensó en la etapa final de sustanciación del juicio oral fue "Por ellos por nosotros por todos \#será justicia".

Así, mientras que en la morfología manifestante apreciamos las conmociones más sobresalientes de la poética pandémica, en la semiología evidenciamos continuidades que obedecen a la construcción a partir del TCVM de una trama de enunciación y visibilidad del problema de la violencia letal sobre los jóvenes de sectores populares de la ciudad ${ }^{12}$ a la vez que la posibilidad de transversalización de esta problemática a los distintos sectores sociales.

\section{Políticas estéticas sobre la muerte Joven}

Los recursos expresivos artísticos oscilaron entre prácticas visuales urbanas, virtuales, audiovisuales, performáticas y festivas. En esta ocasión nos abocamos a específicas intervenciones visuales urbanas que interesa poner en relación.

Las pintadas a mano alzada o mediante stencil (pintadas-stencil ${ }^{13}$ ) distinguieron al repertorio por el TCVM. Las primeras se destacaron por su carácter textual y estamparon consignas emblemáticas. En función de su contenido, distinguimos dos tipos predominantes. En primer lugar, pintadas en memoria que, inspirados en la clasificación que realiza Kozak respecto de los graffitis, definimos como "expresiones de una memoria colectiva que no quiere olvidar a sus muertos" (2004, p. 156). Muertos que, comúnmente, se deben a balas policiales, a enfrentamientos entre bandas o hinchadas, entre otros tipos de muertes violentas. Estas expresiones entablan un diálogo con aquél al que recuerdan, un rasgo epistolar que posee un doble destinatario: el muerto y el lector (2004, p. 156). Entre ellas ubicamos, por ejemplo, la inscripción "Jere, Mono y Patom presentes".

En segundo término, pintadas de arenga que, además del carácter de denuncia que explícita o implícitamente tuvieron todas las consignas, convocaban a continuar y propagar la lucha, así como a la conformación de un colectivo manifestante. Entre ellas podemos mencionar consignas como "Jere Mono Patom. No están solos", "Nos bajan uno, nos levantamos miles", "Justicia por Patom, Jere y Mono. Transformar el dolor en lucha. Multiplicar sus sueños!", "Por ellos por nosotros por todos. Será justicia”.

Las pintadas-stencil fueron las más recurrentes en concordancia con la preeminencia contemporánea de la técnica del stencil entre los recursos expresivos de los movimientos sociales, elección concomitante al predominio de las marchas como metodología de protesta privilegiada ya que esta técnica garantiza la velocidad de ejecución exigida por la circulación del cuerpo manifestante. Demanda una corporalidad ágil que auspicia una economía efectiva de tiempos y recursos si cotejamos esta inversión corporal con la capacidad de expansión, incluso de saturación que posibilita. Así, la presencia corporal se licúa en una omnipresencia gráfica. La simplicidad para su realización, las facilidades de sus modos de aplicación en el espacio público, así como la capacidad sintética y de concisión para plasmar ideas en base a la brevedad textual y la claridad de las imágenes aportan en este sentido.

Las pintadas-stencil se caracterizaron por la preponderancia de la imagen distintiva del repertorio que consistió en la figura, de medio cuerpo, de los tres jóvenes asesinados, retomando una línea estética que encuentra asilo en la tradición retratista de la imaginería política argentina y latinoamericana. En esta misma 
línea, se ubica la escultura realizada en el predio de la cancha de fútbol donde ocurrió el asesinato ${ }^{14}$ y en los murales que fueron otro de los recursos visuales del repertorio. La imagen presente en estas intervenciones exalta características como su juventud (se los muestra haciendo ademanes que acreditan cierto código juvenil barrial); la afectividad (se los expone abrazados) y la alegría (gestos sonrientes) que resaltan la condición de la muerte violenta joven, muerte invertida o muerte salvaje y tributan en la construcción de la figura de víctima para los jóvenes muertos.

De este modo, estas intervenciones tuvieron sentido evocativo, con especial intención de presentificar a los ausentes ${ }^{15}$, en este caso, en tanto víctimas. No hay en ellas exaltación del vacío y de las consecuencias sociales que la ausencia de estos cuerpos produce sino la insistencia en que esos muertos están presentes.

En otros términos, se centraron en la vida, en la trayectoria biográfica, individualizada de esos jóvenes como forma de exigir justicia y castigo a los culpables y, a su vez, en auspiciar la identificación de sus historias con las de otros jóvenes de la ciudad y promover cierta asunción comunitaria del conflicto, cuestión que excede el objetivo de la búsqueda de responsables individuales y la resolución legal. Dicho propósito se refuerza con la semiología manifestante destinada a involucrar a todo el conjunto social en esta problemática. Así, en su confluencia, el repertorio trasciende la comunidad de dolientes que, en reiteradas ocasiones es demonizada y/o desoída socialmente (Verzero, Diz y La Rocca, 2016) gestionando las condiciones emocionales de otro tipo de solidaridad política.

Si bien estas intervenciones visuales urbanas, particularmente en el caso de las pintadas y pintadas-stencils, requieren de una corporalidad ágil, liviana, veloz, se desarrollaron en contextos manifestantes delineados por la presencia masiva (marchas, concentraciones, acampes, etc.). Es decir, los cuerpos ausentes (de los jóvenes) encontraron en la materialidad de la intervención y en el cuerpo colectivo sostén la posibilidad de la presencia.

Dicha vinculación ausencia-presencia se vio alterada en las acciones sucedidas en la gramática pandémica. Días antes al 27 de agosto, la MCVI convocó a la acción "Plantá con nosotros las fotos de lxs pibxs", una instalación en la plazoleta contigua al Centro de Justicia Penal sucedida en el marco de la mencionada Marcha Nacional Contra el Gatillo Fácil.

Los familiares y amigos de las víctimas de violencia institucional plantaron fotos con los rostros de sus seres queridos muertos que fueron reproducidas en blanco y negro en numerosos portafotos construidos con papel y alambre. Esta intervención se superpuso con otra realizada, tiempo antes, por familiares de víctimas de violencia urbana que habían colocado cruces en el mismo sitio. Algunos familiares, de hecho, insertaron las fotos sobre dichas cruces. Un muro de lamentos, una instalación fúnebre que recupera otras acciones del activismo contra la violencia institucional como las marchas negras o el montaje de cementerios frente a dependencias del Poder Judicial. Poéticas del duelo (Vich, 2015) típicas de este último ciclo de protesta local. En este sentido, tal como asevera Butler (2006) el duelo no es una meta política pero sin esa capacidad perdemos el sentido más profundo de la vida que necesitamos para oponernos a la violencia. El duelo público implica reconocer que siempre estamos implicados en vidas y muertes que no son las nuestras, pero que nos interpelan como parte de una comunidad.

Los familiares permanecieron un tiempo acotado sentados al lado de las fotos plantadas, separados entre sí y respetando el perímetro delineado por círculos dibujados con pintura blanca con el propósito de señalar el distanciamiento obligatorio prescripto por las medidas sanitarias. Dicha acción fue fotografiada y compartida en redes sociales, en las que encontró continuidad. Para ese mismo día, se planificó una actividad en la que se proyectaría la lectura conjunta de un documento, que habitualmente se realiza al finalizar la marcha en un escenario destinado a tal fin ante la presencia de los cientos de manifestantes que suelen participar de la movilización cada año. Dicha actividad terminó siendo suspendida y el video de lectura del documento fue compartido sólo a través de redes sociales.

Los cuerpos distanciados, las voces desde la pantalla y la imposibilidad de la presencia masiva del cuerpo manifestante que la multiplicación de las fotos pretendía - de algún modo- compensar, indican algunas 
distinciones necesarias de precisar con las políticas estéticas del TCVM y del activismo contra la violencia institucional pre-pandemia.

Las fotos en banderas, en pancartas, en remeras, reproducidas en caretas/máscaras fueron recursos habituales de estos repertorios y entablaron sinuosos diálogos con lo que Longoni (2010) denominó como las matrices de las políticas visuales del movimiento de derechos humanos argentino. Todas ellas propusieron diferentes relaciones entre los cuerpos de las víctimas y sus familiares y los de los manifestantes sociales.

Tal como sostuvimos en investigaciones recientes, las remeras, como otra capa de la piel, conformaron una prenda clave en la elaboración de los modos de aparecer públicos de los familiares y, al igual que las fotos en pecho de las Madres de Plaza de Mayo, resaltaron la relación filial -y el lazo aurático e intransferible- entre el desaparecido o muerto y quien la porta. Las fotos en banderas, en cambio, apuntaron a armar esa comunidad de ausentes (Chávez Mc Gregor, 2015), todos ahí, juntos, subrayando lo que los liga más que lo que los individualiza. Operación que se extiende, metonímicamente, hacia los familiares que sostienen en conjunto, en la cabecera de las manifestaciones, uno al lado del otro, el artefacto visual que unifica la condición de los muertos y también de los vivos, en tanto comunidad de dolientes y también de sujetos políticos colectivos. Los rostros en caretas/máscaras distribuidos indistintamente entre los manifestantes desdibujan, por su parte, el vínculo filial entre víctima y familiar (Di Filippo y Cristiá, 2021), recuperando las políticas de socialización de la maternidad o del lazo biológico y la generación de dispositivos visuales colectivos (Longoni, 2010) que trascienden la ligazón de sangre y apuntan a colectivizar la lucha.

En cualquier caso, tales recursos en tiempos pre-pandémicos supusieron una relación de proximidad entre la imagen de los jóvenes y los cuerpos de familiares y/o manifestantes.

Otra estrategia se despliega, en cambio, en la acción "Plantá con nosotros" y en la secuencia que compone con el video de lectura del documento compartido a través de las redes sociales así como con la convocatoria a compartir imágenes o fotos de la lucha contra la violencia institucional que mencionamos en apartados anteriores. La encarnadura online (Muller, 2019) completa la corporalidad offline limitada por la emergencia sanitaria pero hay un lazo entre cuerpo ausente-cuerpo presente que se fisura. Las fotos luego de la presencia acotada de los familiares quedaron allí, en la tierra, sin ser sostenidas por otros cuerpos que ofrezcan su materialidad viva para hacer presentes a los ausentes.

Como sostiene Muller (2019) citando a Lovink en las redes sociales el yo es objeto de una constante performance. Los medios digitales incitan a una cultura de la auto-exposición, es decir, a una obsesión colectiva por la gestión de la identidad, un curacionismo del yo, que Balzer (2018) ha señalado como parte de nuestra cotidiana curaduría digital no remunerada. A priori, podemos coincidir en que la participación en estas actividades

forma parte del cultivo del yo, de la modulación de la propia identidad. Sin embargo, otra lectura más benevolente con la tecnopolítica o el tecnoactivismo es posible, particularmente cuando permiten el despliegue de una comunidad de cuerpos que tiene su encarnadura -aunque interdicta por la emergencia sanitaria- en el mundo offline. Es decir, cuando operan como posibilitadoras de una expresividad social cercenada por las dramaturgias del encierro (Proaño Gómez, 2020), cuando son cuerpos mediatizados que insisten a través de las pantallas en ser y sobrevivir. Es decir, cuando la mediatización dinamiza la posibilidad de que acontezca esa comunidad entre cuerpos ausentes, cuerpos presentes y presentificados, cuando permite que algo de la ofrenda impedida pueda acontecer.

\section{REFLEXIONES FINALES}

El análisis de la dimensión estética de la protesta y las prácticas artísticas implicadas en el repertorio por el TCVM nos permitió reconstruir los modos en que se enunciaron y visibilizaron las formas de la violencia letal sobre jóvenes así como se auspició su elaboración o asunción común. La disposición de los cuerpos individuales apuntó a demostrar unidad y fortaleza política así como un especial ánimo guerrero para encarar 
la exigencia de justicia legal. Los dos propósitos semiológicos del repertorio fueron la des-criminalización de los jóvenes y la interpretación del acontecimiento como una problemática de seguridad pública como principal estrategia para interpelar e incluir al cuerpo social en su conjunto. Las pintadas de arenga tributaron en ese sentido. Las pintadas en memoria conmemoraron a los jóvenes-víctimas. Las pintadas-stencils, los murales y las esculturas que tuvieron como imagen central la figura de los tres jóvenes fueron en esa dirección y contribuyeron a construir la imagen de víctimas pero también la demanda de una nueva comunidad política capaz de desidentificarse con el presente, sobre-impresa y exigible a la existente.

El ciclo de protesta inaugurado por este repertorio y sobre el que se inscribió, con sus singularidades, la lucha contra la violencia institucional, experimentó hacia el año 2020 transformaciones. Mientras que una mirada apresurada podría inducirnos a señalar escenarios radicalmente distintos, un análisis más detallado nos condujo a advertir complejamente continuidades y discontinuidades. En la morfología manifestante, es decir en las formas que le dan los cuerpos a la protesta, y en las estrategias estético-políticas entre cuerpos ausentes (vivos y muertos) y presentes (vivos y muertos) alojas en los recursos expresivos artísticos evidenciamos las transformaciones más sobresalientes. No fue así, en cambio, en lo que hace a las espacialidades y temporalidades manifestantes. Allí los repertorios mostraron persistencias, aunque también puntuales novedades, en medio del conmocionado espacio-tiempo pandémico. La semiología, por su parte, selló continuidades antes que diferencias.

En uno y otro caso, la dimensión estética de la protesta y las prácticas artísticas de los repertorios estimularon la capacidad de afección, de solidaridad, de percibir la contigüidad sensible de los cuerpos (vivos y muertos). Ahora bien, ¿qué características singulares adopta esa comunidad de cuerpos (vivos-muertos) en esta fase de la necropolítica y de las necroteatralidades que detona la pandemia?

Marín Pineda sostiene que el exceso numérico de cadáveres que la enfermedad y la muerte masiva impuso invisibilizó otros escenarios de muerte. Refiriéndose al conflicto armado en Colombia, relata la presencia de dos grupos de cuerpos supernumerarios: los muertos por Covid-19 y los muertos por el conflicto armado, el primero obstruyendo la aparición del segundo. Sostiene que la hipervisibilización de la mortalidad viral obedece a que el virus es un ente sin agencia moral, sin posición política, sin clase, sin interés en nada de lo humano (Proaño Gómez y Verzero, 2020). Y que, por esa razón, descarga la responsabilidad sobre esas otras muertes humanas, como las ocasionadas para el caso que nos convoca por violencia policial.

Nos preguntamos ¿cómo se compone esa comunitas entre cuerpos vivos -amenazados por la muerteque reclaman la singularidad de esas vidas arrancadas, con la condición supernumeraria de esas otras vidas perdidas en pandemia? ¿Es posible sin renunciar a las coordenadas de la reinscripción simbólica de esos nombres propios de jóvenes habitualmente sin parte en el orden social, tributar a una política estética y a un pensamiento común de la vulnerabilidad de la vida humana? Si como dice Marín Pineda la pandemia ensancha ese umbral en el dejar morir y hacer morir se confunden en un régimen de acumulación expropiador y aniquilador de la vida humana y no humana, ¿podrá también ser el espacio-tiempo que permita la elaboración estético-política de esos territorios disímiles pero inseparables de la violencia? ¿Será posible desde esos cuerpos vivos sujetos de montaje estético construir un modo de enunciación común para los cuerpos objeto de un modo de acumulación arrasadora de la vitalidad individual y colectiva?

\section{REFERENCIAS}

AA.VV. (2013). Soldaditos de nadie. Jere, Mono y Patóm. Crónica de una lucha. Rosario: Puño y Letra.

Auyero, J. (2002). Fuego y barricadas. Retratos de la beligerancia popular en la Argentina democrática. Nueva Sociedad, $179,144-162$.

Balzer D. (2018). Curacionismo. Cómo la curaduría se apoderó del mundo del arte (y de todo lo demás). Buenos Aires: La marca editora.

Berardi, F. (2014). La sublevación. Buenos Aires: Hekht Libros. 
Blair, E. (2005). Muertes violentas. La teatralización del exceso. Medellín: Universidad de Antioquia.

Butler, J. (2006). Vida precaria: el poder del duelo y la violencia. Buenos Aires: Paidós.

Butler, J. (2017). Cuerpos aliados y lucha politica: hacia una teoría performativa. Barcelona: Paidós.

Cozzi, E. (2016). Entre ajustes de cuentas, problemas de la calle y víctimas inocentes en dos barrios de Santa Fe, Argentina. Pueblos y fronteras, 11(22), 100-119.

Chávez Mac Gregor, H. (2009). Politicas de la aparición: estética y politica. Recuperado de https://www.academia.edu/

Chávez Mac Gregor, H. (2015). Pese a todo, aparecer. Revista Re-visiones, 5, 1-19. Recuperado de https://dialnet.un irioja.es/descarga/articulo/6829453.pdf.

Diéguez Caballero, I. (2007). Escenarios liminares. Teatralidades, performance y política. Buenos Aires: Atuel.

Diéguez Caballero, I. (2013). Cuerpos sin duelo. Iconografias y teatralidades del dolor. Córdoba: DocumentA/Escénica Ediciones.

Didi-Huberman, G. (2014). Pueblos expuestos, pueblos figurantes. Buenos Aires: Manantial.

Di Filippo, M. (2017). "Arte, estética y violencia. Estética de la violencia en el nuevo conflicto y prácticas estético-politicas de protesta de sectores populares y movimientos sociales, en Rosario (2012-2015)”. Ponencia presentada a las Jornadas de Estudios en Cultura y Comunicación - IDAES- UNSAM.

Di Filippo, M. y Cristiá, M. (2021) Máscaras políticas. Visualidades manifestantes: desde los desaparecidos en dictadura a la violencia institucional en democracia. Nawi: arte.diseño.comunicación, 5(1), 97-115. https://ww w.doi.org/10.37785/nw.v5n1.a5

Expósito, M. (2005) La imaginación política radical. El arte, entre la ejecución virtuosa y las nuevas clases de luchas. En Desacuerdos sobre arte, políticas y esfera pública en el Estado español, (2). Recuperado de http://transform.ei pcp.net/transversal/0507/exposito/es.html

Expósito, M. (2014). El arte no es suficiente. En M. Botey y C. Medina (Eds.). Estética y emancipación. Fantasma, fetiche, fantasmagoria (pp. 47-62). México: Siglo XXI.

Expósito, M., Vindel, J. y Vidal, A. (2012). Activismo artístico. AA. VV. Perder la forma humana. Una imagen sísmica de los años ochenta en América Latina. (pp. 43-50). Madrid: Museo Reina Sofía.

Fillieule, O. y Tartakowsky, D. (2015). La manifestación. Cuando la acción colectiva toma las calles. Buenos Aires: Siglo XXI.

Fuentes, M. (2020). Activismos tecnopoliticos. Constelaciones de performance. Buenos Aires: Eterna Cadencia.

Groys, B. (2014). Volverse público. Las transformaciones del arte en el ágora contemporáneo. Buenos Aires: Caja Negra Editora.

Gutiérrez, L. y Cuello N. (2016). Mujeres Públicas: La incomoda lengua del hacer feminista. En Catálogo. Córdoba: MACEC.

Holmes, B. (2005) Transparencia y éxodo. Procesos politicos en las democracias mediadas. Recuperado de http://brian holmes.wordpress.com.

Holmes, B. (2012). Eventwork: La cuádruple matriz de los movimientos sociales contemporáneos. Errata. Revista de Artes Visuales, 7.

Kozak, C. (2004). Contra la pared: sobre graffitis, pintadas yotras intervenciones urbanas. Buenos Aires: Libros del Rojas.

Kozak, C. (Ed.) (2015). Tecnopoéticas argentinas. Archivo blando de arte y tecnología. Buenos Aires: Caja Negra.

Lipovesky, G. y Serroy, J. (2015). La estetización del mundo. Vivir en la época del capitalismo artístico. Barcelona: Anagrama.

Longoni, A. (2007). Encrucijadas del arte activista en Argentina. Ramona, 74, 31-43.

Longoni, A. (2009). Activismo artístico en la última década en Argentina: algunas acciones en torno a la segunda desaparición de Jorge Julio López. Errata, 0, 16-35.

Longoni, A. (2010). Arte y Política: Políticas visuales del movimiento de derechos humanos desde la última dictadura: fotos, siluetas y escraches. Aletheia, 1(1). Recuperado de http://www.memoria.fahce.unlp.edu.ar/art_revistas/ pr.4278/pr.4278.pdf 
Muller, N. (2019). Performance del no muerto. Vida y muerte en las redes sociales y el arte contemporáneo. En A. Downey (comp.) La primavera árabe y el invierno del desencanto. Prácticas artisticas y medios digitales en el norte de África y Oriente Medio. Buenos Aires: Ripio.

Pérez Balbi, M. (2020). Habitar/Confabular/Crear. Activismo artístico en La Plata. La Plata: Editorial de la Universidad de La Plata.

Proaño Gómez, L. y Verzero, L. (comps.) (2020). Mutis por el foro. Artes escénicas y politica en tiempos de pandemia. Editorial ASPO (Aislamiento Social Preventivo y Obligatorio). Recuperado de https://www.academia.edu/44 767637/Mutis_por_el_Foro.

Rancière, J. (2005). Sobre politicas estéticas. Barcelona: Universidad Autónoma de Barcelona - Museo de Arte Contemporáneo de Barcelona.

Rancière, J. (2007). El desacuerdo. Politica y filosofia. Buenos Aires: Nueva Visión.

Rancière, J. (2009). El reparto de lo sensible. Estética y política. Santiago de Chile: LOM Ediciones.

Rosler, M. (2017). Clase cultural. Arte y gentrificación. Buenos Aires: Caja Negra Editora.

Scribano, A. y Cabral, X. (2009). Política de las expresiones heterodoxas: el conflicto social en los escenarios de las crisis argentinas. Convergencia, 16 (51), 129-155.

Verdú, V. (2003). El estilo del mundo. La vida en el capitalismo de ficción. Barcelona: Anagrama.

Verzero, L., Diz, M.L. y La Rocca, M. (2016). Manifestaciones artísticas y movilizaciones sociales en la historia reciente de América Latina. Clepsidra. Revista Interdisciplinaria de Estudios sobre Memoria, 3(6), 6-9.

Vich, V. (2004). Desobediencia simbólica. Performance, participación y política al final de la dictadura Fujimorista. En A. Grimson (comp.), La cultura en las crisis latinoamericanas (pp. 63-80). Buenos Aires: CLACSO.

Vich, V. (2015). Poéticas del Duelo. Ensayos Sobre Arte, Memoria y Violencia Política en el Perú. Lima: Instituto de Estudios Peruanos.

\section{Notas}

1 Un análisis preliminar y más extenso sobre este caso puede encontrarse en DI FILIPPO, M. (2017).

2 El Movimiento 26 de Junio fue una organización social rosarina de base territorial perteneciente al Frente Popular Darío Santillán (FPDS), un movimiento social argentino creado en el año 2004 a partir de la unión de diferentes organizaciones sociales, estudiantes, políticas y culturales. Los miembros del FPDS coinciden en afirmar que las primeras articulaciones tuvieron inicio en el 2002 luego de la Masacre de Avellaneda. El FPDS se inscribió en una perspectiva política autónoma o autonomista, se compuso de organizaciones de desocupados o piqueteras, agrupaciones estudiantiles, un incipiente sector rural y de trabajadores ocupados, colectivos y trabajadores de la cultura, activistas de las redes de trueque y organizaciones vecinales.

3 La Multisectorial Contra la Violencia Institucional es una organización de derechos humanos creada en la ciudad de Rosario en el año 2016, compuesta por familiares de jóvenes víctimas de violencia institucional y organizaciones políticas, sociales, sindicales, académicas, de derechos humanos y culturales.

4 Jonatan Herrera, de 23 años, fue asesinado por la policía santafesina el 4 de enero de 2015 en Barrio Tablada como consecuencia de una balacera en la que intervinieron agentes de la Policía de Acción Táctica (PAT) y del Comando Radioeléctrico (CRE), mientras lavaba su auto en la vereda de su casa

5 Gerardo "Pichón" Escobar, de 23 años, fue desaparecido y asesinado por patovicas y policías de la Provincia de Santa Fe, a la salida del boliche La Tienda la madrugada del 14 de agosto de 2015. Su cuerpo sin vida también fue arrojado al río Paraná

6 Maximiliano Zamudio, de 16 años, fue asesinado el 27 de mayo de 2015 por un agente de la Prefectura Naval Argentina en Barrio Tablada.

7 David Campos y Emanuel Medina de 28 y 32 años respectivamente, el 23 de junio de 2016 al regresar de los festejos por un nuevo campeonato de Boca Juniors, fueron perseguidos sin motivo en la zona sur de la ciudad por agentes del Comando Radioeléctrico y de la Policía de Acción Táctica y fusilados luego de que su auto colisionara contra un árbol al ser encerrado por los vehículos policiales.

8 El Movimiento 26 de Junio a partir del año 2013 confirmó el Frente para la Ciudad Futura, una alianza electoral luego llamada partido Ciudad Futura, que desde el año 2015 cuenta con representación legislativa en el Consejo Municipal de la ciudad de Rosario. 
9 Dicha cuestión quedó coronada en los cánticos que acompañaron el repertorio, tales como el siguiente: "Y dale alegría, alegría a mi corazón/la sangre de los caídos se reveló/ ya vas a ver/ las balas que nos tiraste van a volver/y si señor/ vamos a vengar a Jere, Mono y Patom".

10 En el Informe de la Comisión de Información e Investigación del Triple Crimen de Villa Moreno (Sala de la Comisión de Derechos y Garantías, Cámara de Diputados de la Provincia de Santa Fe) del 28/11/2012 puede encontrarse una descripción de la figura del "ajuste de cuentas". Los artículos periodísticos más significativos al respecto fueron "Tres personas fueron acribilladas a balazos en zona sur”, en La Capital, 01/01/12 y “Asesinaron a 3 jóvenes en Rosario mientras festejaban el año nuevo", en Clarín, 01/01/12. Según datos del Observatorio de Derechos Humanos del Centro de Investigaciones Juan Carlos Gardella de la Facultad de Derecho de la Universidad Nacional de Rosario, considerando el 2011 y hasta el 15 de julio del 2012, el 50\% de los asesinatos cometidos en Rosario eran caratulados como "ajuste de cuentas". Para un análisis detallado de esta cuestión puede consultarse también Cozzi (2016).

11 Comunicado del Movimiento 26 de Junio, 01/01/2012.

12 En un comunicado del 08/01/2012 titulado "El Ejecutivo Provincial garantizará la seguridad de familiares y compañeros de los tres militantes asesinados", sostienen: "El feroz asesinato de estos pibes no es un hecho aislado en las barriadas de nuestro país, sino que es parte de la violencia cotidiana que vive la juventud de los sectores populares. Esta realidad está cercada por el accionar de un entramado mafioso que integran narcotraficantes, barrabravas, punteros políticos y fuerzas de seguridad que tejen con total libertad sus redes de negocios, favorecidos por la corrupción estatal y resguardando sus crímenes en la intencionada estigmatización que asocia a nuestro pibes con la delincuencia. Las políticas públicas de seguridad de los últimos años se han caracterizado en aumentar la presencia de las fuerzas de seguridad en las calles, sin resolver los problemas de fondo que evidencian que estas mismas fuerzas de seguridad son actores protagónicos en el entramado del crimen organizado".

13 Utilizamos este término bajo la consideración que realiza Kozak (2004) respecto a que el stencil es una técnica y no un tipo de intervención en sí mismo. En su caso utiliza la denominación "graffiti-esténcil”.

14 La escultura contiene la misma imagen precedida por la consigna "No están solos".

15 En el comunicado "La memoria se sube a las paredes" del 17/01/2012 el Movimiento 26 de Junio sostiene que pintaron el mural para hacer nuevamente presentes a los jóvenes en el barrio. Vale mencionar también como ejemplo elocuente de esta estrategia, una producción audiovisual realizada por el Movimiento como parte del repertorio que se denomina “Serán eternos". Puede visionarse en: Defensoría de Niñas, Niños y Adolescentes Santa Fe (18/12/2013) Serán eternos. Youtube. https://www.youtube.com/watch?v=yYpKTVEJe20 